\title{
Assessing the Effect of Curing Conditions, Specimen Type, and Superabsorbent Polymers in Compressive Strength and Abrasion of Pervious Concrete
}

\author{
Dennis Daddino, Cristián Gaedicke, Ph.D., P.E., Fadi \\ Castronovo, Ph.D., and Saeid Motavalli, Ph.D., P.E. \\ California State University, East Bay \\ Hayward, CA
}

\author{
David Liguori \\ Bay Area Pervious Concrete \\ San Carlos, CA
}

The effect of curing conditions, specimen type, and the use of super absorbent polymers on the Compressive Strength and Abrasion of Portland Cement Pervious Concrete was evaluated. Five different mixtures, using different water/cement ratios, and the addition of polypromancic based acid and polyacrylate based super absorbent polymers were tested. Half of the specimens were cured in a temperature-controlled room at higher temperature and lower humidity to simulate field conditions. Specimens that were cured in these harsher conditions showed reduced compressive strength in the range of $34 \%$ to $35 \%$ for cast cylinders, and $27 \%$ to $67 \%$ for cores when compared to specimens cured under ideal conditions in the lab. These samples also had 3.14 to 3.2 times the abrasion damage compared to laboratory cured samples of similar porosities.

Key Words: pervious concrete, super absorbent polymers, field cured, porosity, compressive strength, abrasion

\section{Introduction}

Pervious concrete has become an increasingly important building material in the relatively new, sustainable construction industry. Over the last few decades, this environmentally friendly material has been used instead of traditional pavements to help combat environmental problems such as excessive stormwater runoff and increasing heat island effects (Kevern et al.,2009) as well as in eliminating the need for extensive drainage systems that often come with large paving projects. Installing pervious concrete instead of curbs, gutters, drain inlets, piping, and retaining ponds can save private owners and municipalities large amounts of time, space, and money while improving the quality of life for people adjacent to these projects. 
Pervious concrete is comprised of water, admixtures, coarse aggregate, and Portland cement that, when combined, creates a series of interconnected voids that allow water to drain while maintaining sufficient structural integrity to allow for practical uses in construction (ACI 522, 2010). The cement paste coats the coarse aggregate, bonding them together while leaving voids. The lack of significant fine aggregates in pervious concrete mixes allows the interconnected void range to reach a ratio of $15 \%$ to $25 \%$. This range allows for good drainage while maintaining structural integrity. Some admixtures used in pervious concrete designs include air entrainment agents, water reducers, hydration stabilizers, and Superabsorbent Polymers (SAP). Super absorbent polymers, in particular, have shown promise in improving the performance of pervious concrete pavements (PCP).

Pervious concrete has not been extensively used due to performance concerns. The increased risks of surface raveling and reduced durability are a few primary concerns with Portland cement pervious concrete pavements (Zhong \& Wille, 2015). This risk is especially critical when the concrete is subjected to harsh temperature and moisture conditions. One active research area has been to enhance the internal curing of pervious concrete to improve its performance. Internal curing can be defined as the "incorporation of a curing agent serving as an internal reservoir of water, gradually releasing it as the concrete dries out" (O. Mejlhede Jensen, 2013), This slow release of water ensures proper curing of the cement paste and bone of the coarse aggregate particles.

One initial approach to achieve internal curing in pervious concrete was to use small quantities of lightweight sand and pre-wetted lightweight aggregates as an effective internal curing agent (Lund $e t$ al.,2016; Kevern, 2013; Kevern \& Nowasell, 2017). This method has the drawback that having an extra material such as prewetted lightweight fine aggregate available in the concrete plant poses logistical problems, and that lightweight aggregates can reduce the strength and modulus of elasticity of the concrete.

An alternative approach for internal curing is the addition of Superabsorbent Polymers (SAP) in pervious concrete. Superabsorbent polymers (SAP's) are polymeric materials that can hold 1,500 grams of water per 1 gram of SAP (RILEM-TAC 225-SAP, 2012) but, at the extreme, these polymers can take on water at a rate of up to 5,000 times their own weight (Jensen, 2013). They consist of hydroxyl (-OH), carboxyl (-COOH), and other hydrophilic groups that form a three-dimensional cross-linked structure They are predominately used in the hygiene industry for products like diapers. The expectation in using SAP's in pervious concrete would be for the SAP to absorb large amounts of water and then release it when the mix is exposed to the elements, therefore providing the internal curing needed by the concrete. After the internal curing process is complete, the SAP becomes an inanimate part of the concrete, unable to duplicate the hydration and release process.

While SAP's have been tested in conventional and high-performance concrete to reduce shrinkage (Kong, Xiang-ming et al., 2015), and promote durability (Faping Li, 2018), there is limited experimental research in the literature focused on the use of SAP's in pervious concrete.

Kevern \& Farney (2012) evaluated the potential of SAP as a means to reduce the need for curing pervious concrete under plastic. They evaluated compressive strength, shrinkage, unit weight, voids, permeability, and rotary cutter surface abrasion. They found that the mixtures containing the SAP had better workability and were stronger at equal void contents. They also observed reduced shrinkage, moisture loss, and abrasion. Their uncured SAP field mixture had performance equal to the control mixture cured under plastic. Although preliminary, their results show that SAP has good potential to reduce curing requirements for pervious concrete under many environmental conditions. 
Kevern and Sparks (2013) evaluated different low-cost options to reduce PCP surface raveling. They found that the durability of the internally cured mixture using SAP's was superior to that of the traditional mixture. Material analysis showed that modifying a mixture to include superabsorbent polymer was the lowest-cost option. The surface durability was tested using the ASTM C944 rotary cutter method.

While the existing research shows the potential of SAP's in pervious concrete pavements, many questions still remain. Of particular interest is the comparison between different SAP's and concrete specimen types, such as cast cylinders and cores.

\section{Research Objective}

The primary objective of this research was to assess the effect of harsh environmental conditions (temperature and moisture) on pervious concrete strength and durability and to evaluate the effectiveness of the super-absorbent polymers as an internal curing agent in pervious concrete cast cylinders and cores. The concrete performance using different curing methods, an optimal curing method versus simulated harsher field curing conditions, was also measured.

\section{Experimental Program}

\section{Materials}

The materials utilized in this experiment consisted of Type 2 Portland Cement, coarse aggregate, a hydration stabilizer, two types of superabsorbent polymers, and potable water. The aggregate was sourced from a quarry in the Pleasanton, CA area, and met the requirements of ASTM C33/C33M, its physical properties and sieve analysis are shown in Tables 1 and 2, respectively. The admixtures fulfilled the requirements of ASTM C494/C494M.

Table 1. Physical Properties of Aggregates

\begin{tabular}{c|l|c|c}
\hline Property & Standard & Unit & Value \\
\hline & & & \\
\hline Unit Weight & ASTM C29 & $\mathrm{lb} / \mathrm{ft}^{3}$ & 100.5 \\
Water Absorption & ASTM C127 & $\%$ & $1.293 \%$ \\
Bulk Specific Gravity $(a)$ & ASTM C127 & $\mathrm{n} / \mathrm{a}$ & 2.649 \\
Bulk Specific Gravity $(b)$ & ASTM C127 & $\mathrm{n} / \mathrm{a}$ & 2.615 \\
\hline
\end{tabular}

(a) saturated surface dry condition; (b) oven dried condition

Table 2. Sieve Analysis of Coarse Aggregate

\begin{tabular}{|c|c|c|c|c|}
\hline Sieve & $3 / 4 "$ & $1 / 2 "$ & 3/8" & $1 / 4 "$ \\
\hline Percent Passing & $100 \%$ & $62.8 \%$ & $13 \%$ & $1.1 \%$ \\
\hline
\end{tabular}




\section{Experimental Plan and Mixture Proportioning}

This study utilized five different mixes, all designed according to ACI 522R-10 (ACI 522, 2010). Two mixes contained no SAP and had water-cement ratios of 0.3 and .40. In the next step, there was a set of 0.4 water-cement ratio mixes using a sodium polyacrylate based SAP (identified as S), one with a low dose ("L") of 1.8 ounces (Mix ID: 0.4LS) and one with high does ("H") of 3.5 ounces per cubic yard (Mix ID: 0.4HS). The last mixture (Mix ID: 0.4HM) was a .40 water-cement ratio mix that contained 3.5 ounces of the SAP identified as HM. This SAP contains ground granulated blastfurnace slag, amorphous silica, crystalline silica, and polypromancic acid. We chose $\mathrm{S}$ and $\mathrm{HM}$, as they are the leading SAP's currently being used by contractors in the field. All mixture proportions and their fresh density, according to ASTM C1688 (ASTM, 2012), are shown in Table 3.

\section{Table 3. Experimental Plan}

\begin{tabular}{l|c|c|c|c|c}
\hline W/C ratio & $\mathbf{0 . 3}$ & \multicolumn{4}{|c}{$\mathbf{0 . 4}$} \\
\hline Polymer Type & & & \multicolumn{2}{|c|}{$\begin{array}{c}\text { SAP 1 (S) } \\
\text { (LS \& HS) }\end{array}$} & $\begin{array}{c}\text { SAP 2 } \\
\text { (HM) } \\
\text { (HM) }\end{array}$ \\
\hline Polymer Dose & none & None & Low & High & Low \\
\hline Mix ID & 0.3 & 0.4 & $0.4 \mathrm{LS}$ & $0.4 \mathrm{HS}$ & $0.4 \mathrm{HM}$ \\
\hline Polymer (oz) & 0 & 0 & 1.8 & 3.5 & 3.5 \\
\hline Coarse Agg (lb) & 2841 & 2841 & 2841 & 2841 & 2841 \\
\hline Cement (lb) & 475 & 410 & 410 & 410 & 410 \\
\hline Water (lb) & 143 & 164 & 164 & 164 & 164 \\
\hline Hydration Stabilizer (oz) & 5 & 5 & 5 & 5 & 5 \\
\hline Fresh Density (lb/ft $\left.{ }^{3}\right)$ & 111.8 & 118.9 & 117.4 & 116.2 & 116.3 \\
\hline
\end{tabular}

\section{Mixing, Casting, Compaction and Curing Methods}

All five mixes were prepared in a rotating steel drum concrete mixer. For all mixes, the entirety of the aggregate and half of the water were combined and mixed for one minute. Then, the balance of the water and all the cement were added, and mixed for three minutes. The admixtures were then, added and the drum rotated for an additional four minutes. The mix was then allowed to rest for four minutes before a final two-minute re-mix to complete the process. Each mixture was used to cast six 4"X 8" cylinders to be cured under lab conditions and another set of six 4"X 8" cylinders and one 24" X 24" $\mathrm{X} 8$ " wood formed pervious concrete panel to be cured under conditions representing the field.

The cylinders in the study were compacted by proctor hammer, by filling the cylinder roughly halfway and performing 20 drops of a standard $5.5 \mathrm{lb}$ proctor hammer with a fall height of $12 \mathrm{in}$. The force of the hammer was evenly distributed over the cylinder with the use of a 3/4 in. thick plywood plate cut in the diameter of the test cylinders. After the bottom half was filled and compacted, the remainder of the cylinder was then filled to slightly over the top and compacted with 20 additional drops. Any excess pervious concrete at the top was struck off smooth, such that any minor voids were filled. 
The 24" X 24" X 8" pervious concrete panels that produced the drilled core specimens were compacted with a roller that produced $100 \mathrm{lb} / \mathrm{ft}^{2}$ of pressure, in a manner that duplicated a field installation, then placed in an environmental chamber. The panels were poured to $1 / 2$ "above the tops of the forms and troweled smooth. A roller was then passed over the surface three times the long way and three times the narrow way. After compaction, the panels were covered with plastic sheeting. The cores were extracted after curing for 28 days.

\section{Curing}

After 48 hours, all forms/cylinders were stripped, and the specimens were prepared for curing. Half of the cylinders ( 6 total, 3 for compressive strength and 3 for durability) were cured by placement into saturated limewater. We refer to this process as "laboratory curing".

The other half of the cylinders ( 6 total, 3 for compressive strength and 3 for durability) and the panels that would produce the cores were placed into a temperature-controlled room set to represent harsh temperature and humidity conditions that could occur in the field. This process referred to in this publication as "simulated-field" curing. The process consisted of placing the cylinders and pervious concrete panel in a chamber at 85 degrees Fahrenheit and an average humidity of $68.7 \%$. The panels were left uncovered and exposed for $30 \mathrm{~min}$, then covered with plastic for 48 hours, then uncovered again for the duration of the 28-day curing period.

\section{Test Methods and Results}

Porosity: The porosity of the pervious concrete was established using the process created by Montes et al. (2005). First, the length and diameter of the cylinders, both cast and cored, were measured. Then the dry and submerged weights were recorded. This data was used in the equation below to calculate the porosity.

Where:

$P=$ porosity, $\%$

$W_{l}=$ weight under water, $\mathrm{g}(\mathrm{lb})$

$W_{2}=$ air-dried weight, $\mathrm{g}(\mathrm{lb})$

Vol $=$ volume of sample, $\mathrm{cm}^{3}\left(\mathrm{in}^{3}\right)$

$P_{w}=$ density of water $@ 21^{\circ} \mathrm{C}, \mathrm{kg} / \mathrm{cm}^{3}\left(\mathrm{lb} / \mathrm{in}^{3}\right)$

$$
P=\left[1-\left(\frac{W_{2}-W_{1}}{P_{w} \operatorname{Vol}}\right)\right] \times 100(\%)
$$

Compressive Strength: The compressive strength was established using ASTM C39 Standard Test Method. Both ends of each cylinder were capped with a sulfur compound to ensure a flat, consistent surface for uniform force application. Force was applied at a pace of $0.25 \pm 35 \pm 7 \mathrm{psi} / \mathrm{s}$ until the sample fractured.

Abrasion: was tested using a Los Angeles machine per ASTM C1747/C1747M (ASTM, 2012). The initial mass of a set of three 4"X4"- cylinders of each mix was measured and recorded as the initial weight of the sample $\left(W_{l}\right)$. The set was then put in the Los Angeles drum without steel spheres and rotated for 167 revolutions at a rate of 30 revolutions per minute. All pieces that would not pass through a 1 " sieve were then weighed, to record the final weight of the sample $\left(W_{2}\right)$. An example of abrasion specimens before and after the test is shown in Figure 2(b). The mass loss was then calculated using the following formula: 
Where:

$M L=$ Mass loss, \%

$W_{l}=$ Initial weight of sample, $\mathrm{lb}$

$W_{2}=$ Final weight of sample, lb

$$
M L=\frac{W_{1}-W_{2}}{W_{1}} \times 100
$$

\section{Analysis of Results}

Figure 1 shows the compressive strength versus porosity achieved by the mixtures under different curing \& compaction scenarios. The cast cylinder specimens compacted with the proctor hammer and cured underwater are shown in the top plot (Lab - Cast). The cylinder specimens compacted with the proctor hammer and cured under simulated-field conditions are shown in the middle plot (Field Cast), and the core specimens extracted from the concrete panels cured under simulated-field conditions are shown in the bottom plot (Field - Core). For each plot, a linear regression curve was added. The dotted line in the middle and bottom plots represent the linear regression curve for the proctor hammer and cured underwater (Lab - Cast) specimens, added for comparison purposes. For all curing conditions, the compressive strength decreased as the porosity increased, as observed by Deo et al. (2011).

The comparison of the top and the middle plot in Figure 1, which only includes cast cylinders compacted by proctor hammer, show that curing conditions have a significant effect on the compressive strength of the pervious concrete at different porosity levels. The cylinders cured under laboratory conditions (Lab - Cast) were significantly stronger than the cylinders that were cured under field-simulated conditions (Field - Cast), by 34\% (1921 psi vs. 2572 psi) to 35\% (1075 psi vs 1456 psi), at low (22\%) and high (34\%) porosity, respectively.

The comparison between the top and the bottom plot in Figure 1 shows that at a low porosity of $22 \%$, the cylinders compacted by proctor hammer and cured under laboratory conditions had $27 \%$ higher strength (2064 psi vs. 2572 psi) compared to simulated-field cured cores. A similar scenario was seen at high (34\%) porosity, where the difference was 67\% (872 psi vs. 1456 psi).

When comparing the middle and bottom plots in Figure 1, it can be seen that cast cylinders and cores cured under simulated-field conditions (Field - Cast \& Field - Core) had very similar strength for equivalent porosities. This differs from previous research such as Gaedicke et al. (2014), which suggests that under the same curing conditions, cores should have a compressive strength that is significantly lower than that of cast cylinders at the same porosity.

The cores extracted from panels made with mixtures using SAPs had a higher degree of workability and lower porosity, which lead to higher strength and performance in simulated field conditions. Our current results do not allow us to observe significant differences in the compressive strength of the mixtures using the $\mathrm{S}$ and the HM SAP. This holds true, even as all mixtures had the same volume of cement paste and were subjected to the same compaction effort.

Figure 2(a) shows the mass loss versus porosity achieved by the mixtures under different curing and compaction scenarios. The mass loss was measured after 167 abrasion cycles. The figure has three plots, the specimens compacted with the proctor hammer and underwater cured (laboratory conditions) are shown in the top plot (Lab - Cast). The cylinder specimens compacted with the proctor hammer and cured under simulated-field conditions are shown in the middle plot (Field - Cast), and 
the core specimens extracted from the concrete panel cured under simulated-field conditions are shown in the bottom plot (Field - Core). For each plot, a linear regression curve was added. The dotted line in the middle and bottom plots represents the linear regression curve for the proctorhammer compacted, underwater cured (Lab - Cast) specimens, added for comparison purposes. The measure of Abrasion Durability is mass loss; thus, a higher value indicates a higher degree of damage on the sample. In the field, this would increase the likelihood of raveling of pervious concrete pavement.

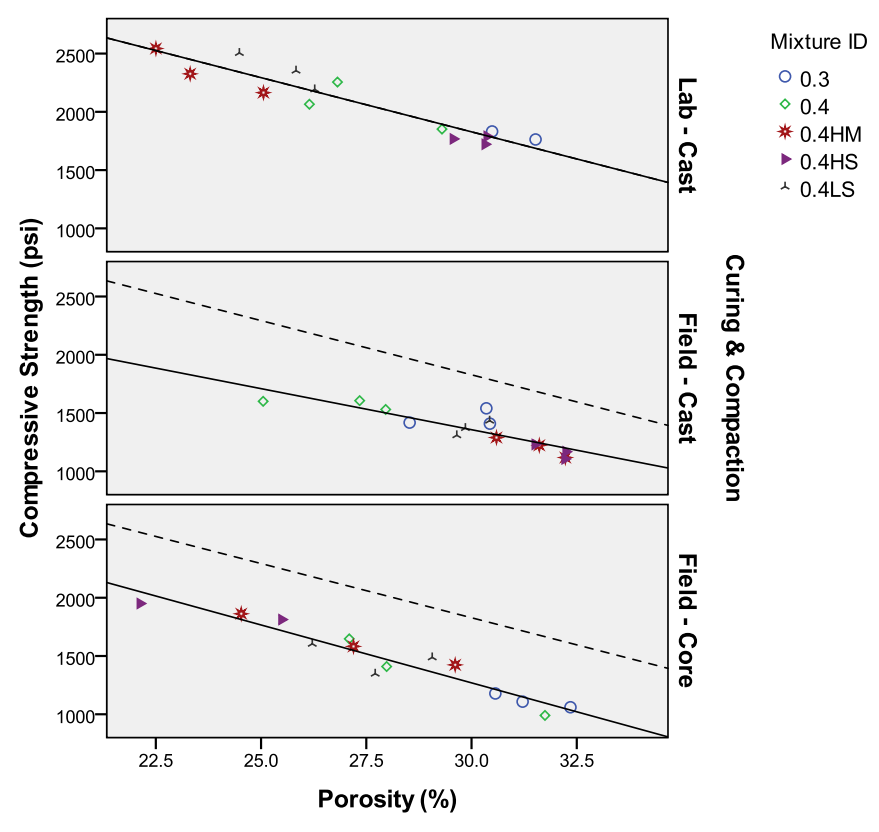

\section{Figure 1. Compressive Strength (psi) versus Porosity (\%) relationships for different mixtures, specimen types, and curing methods.}

For all specimen types and curing regimes, the mass loss (i.e., damage) increases when the porosity of the specimens increases. This trend is visible for all specimen types and curing conditions. Shu et al. (2011) found the same trend while performing Cantabro testing of pervious concrete cylinders that did not contain SAP.

However, when comparing the top and the middle plot in Figure 2(a), it can be seen that the initial mass loss at low permeability and its rate of deterioration with increased porosity is far higher in cylinders that were cured under simulated-field conditions (Field - Cast) as compared to cylinders cured under laboratory conditions (Lab - Cast). For instance, at 22\% porosity, the regression curves predict a mass loss of just $16.6 \%$ in lab cured cylinders compared to $57.2 \%$ in simulated-field cured cylinders, which is a 3.45 times difference. At a higher porosity of $34 \%$, the regression curves predict a mass loss of $27.6 \%$ in lab cured cylinders compared to $88.3 . \%$ in simulated-field cured cylinders, which is a 3.20 times difference. It is unequivocal that the mass loss is considerably higher at comparable porosities for field cured specimens versus the samples cured in the ideal conditions of the lab. Kevern et al. [13] found similar results. That study found higher surface abrasion in simulated-field curing conditions compared to specimens cured in the lab. 
The results on field cured cores shown in the bottom plot in Figure 2(a) confirm the trends seen in the middle plot. Field cured cores have a degree and a rate of deterioration that increases with porosity. However, this rate (slope) is far higher than in cylinders that were cured under laboratory conditions (Lab - Cast). For instance, at 22\% porosity, the regression curves predict damage of just $16.6 \%$ in lab cured cylinders and $52.0 \%$ in simulated-field cured cores, which is 3.14 times higher. At $34 \%$ porosity, the core specimens fail.

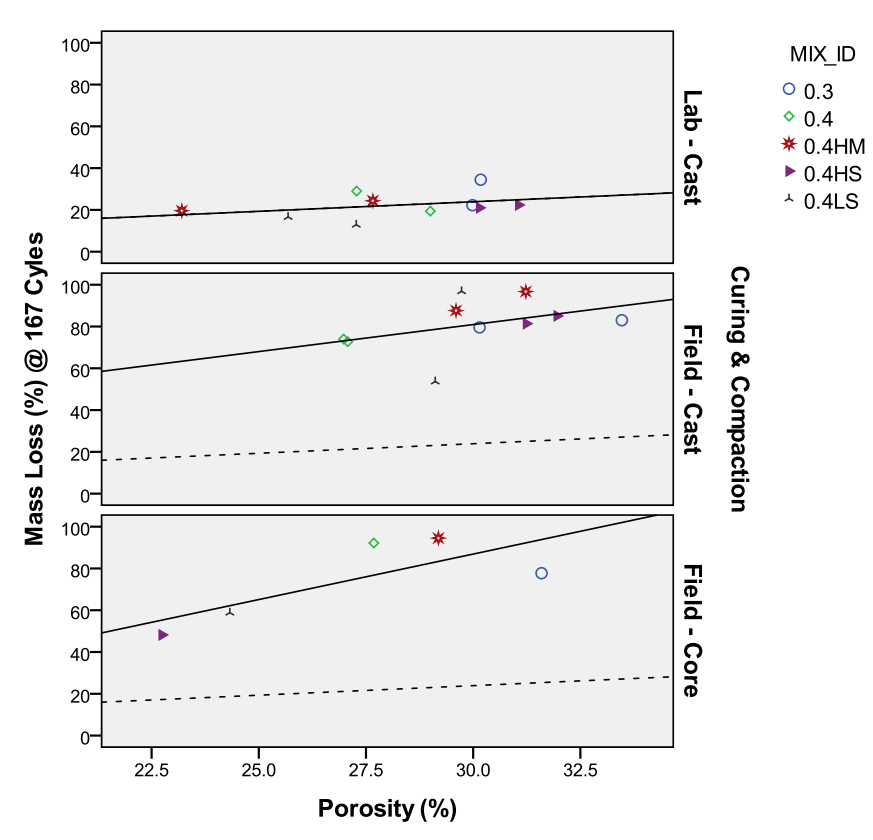

(a)

\section{Specimens Specimens after before testing the test $\left(\mathrm{W}_{2}\right)$}

$\left(\mathrm{W}_{1}\right)$

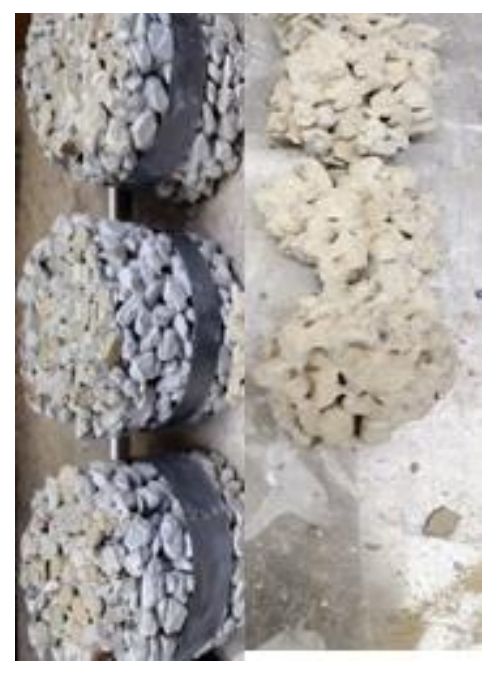

(b)

Figure 2(a). Mass Loss (\%) versus Porosity (\%) relationships for different mixtures, specimen types, and curing methods.(b) Specimens before and after the test.

\section{Conclusions}

Specimens that were cured under harsher temperature and humidity conditions representing field conditions showed reduced compressive strength in the range of $34 \%$ to $35 \%$ for cast cylinders, and $27 \%$ to $67 \%$ for cores. These samples also had 3.14 to 3.2 times the mass loss (i.e., lower abrasion durability) compared to laboratory cured samples of similar porosities. Field cured cores deteriorate at a rate that is far faster than cylinders that were cured under laboratory conditions (Lab - Cast). For instance, at $22 \%$ porosity, the predicted damage of simulated-field cured cores is 3.14 times higher. At a $34 \%$ porosity, the core specimens fail.

Our research showed that cores extracted from panels made with mixtures using SAPs had a higher degree of workability and lower porosity, which lead to higher strength and performance in simulated field conditions. In addition, field cores using HM SAP had lower porosity and lower mass loss (i.e. higher durability) compared to the control mixture. Therefore, we confirmed that SAP has the 
potential to enhance the performance of PCP in the field. Future research should include a larger number of mixtures using different SAP dosage.

\section{References}

American Concrete Institute (2010). Pervious Concrete. ACI 522 Committee Report. Farmington Hills, MI.

ASTM Standards (2012). Volume. 04.02. West Conshohocken, PA.

Deo, O. \& Neithalath, N. (2011). Compressive Response of Pervious Concretes Proportioned for Desired Porosities. Construction and Building Materials, 25 (11), 4181-4189.

Gaedicke, C., Marines, A. \&Miankodila, F. (2014). A Method for Comparing Cores and Cast Cylinders in Virgin and Recycled Pervious Concrete. Construction and Building Materials, 52 (2), 494-503.

Jensen, M. (2013). Use of superabsorbent polymers in concrete. Concrete International, 35 (1), 48-52.

Kevern, J. T., Haselbach, L., \& Schaefer, V. R. (2009). Hot Weather Comparative Heat Balances in Pervious Concrete and Impervious Concrete Pavement Systems, presented at the second international conference on countermeasures to urban heat islands, Berkley, CA, 2009.

Kevern, J. T. (2013). Reducing the Curing Requirements of Pervious Concrete Using Prewetted Lightweight Aggregate for Internal Curing. Report submitted to Expanded Shale, Clay, and Slate Institute. December 20, 2013. URL https://www.escsi.org/wp-content/uploads/2017/10/PerviousReport-Kevern.pdf

Kevern, J.T. \& Sparks, D. J. (2013). Low-Cost Techniques for Improving the Surface Durability of Pervious Concrete. Transportation Research Record: Journal of the Transportation Research Board, 2342, 83-85

Kevern, J.T.\& Farney, C. (2012). Reducing Curing Requirements for Pervious Concrete with a Superabsorbent Polymer for Internal Curing. Transportation Research Record: Journal of the Transportation Research Board, 2290, 116-118.

Kevern, J. T. \& Nowasell, Q. C. (2017). Internal Curing of Pervious Concrete Using Lightweight Aggregates. Construction and Building Materials. 161, 229-235.

Kong, X., Zhang, Z-L. \& Lu, Z-C. (2015). Effect of pre-soaked superabsorbent polymer on shrinkage of high-strength concrete. Materials and Structures/Materiaux et Constructions, 48(9), 2741-2758.

Li, F. Liu, J., Yuan, J., He, X. \& Zhang, R. (2018). Durability of concrete modified with superabsorbent polymers. Materials Performance, 57 (3), 54-58.

Lund, M. S. M., Kevern, J. T., Schaefer, V. R. \& Hansen, K. K. (2016). Mix Design for Improved Strength and Freeze-thaw Durability of Pervious Concrete Fill in Pearl Chain Bridges. Materials and Structures. 50 (42). https://doi.org/10.1617/s11527-016-0907-4

Montes, F., Valavala, S., \& Haselbach, L. M. (2005). A New Test Method for Porosity Measurements of Portland Cement Pervious Concrete. Journal of ASTM International, 2 (1), 1-13.

RILEM .(2012). Applications of Superabsorbent Polymers (SAP) in Concrete Construction. RILEM State-of-the-Art Report Prepared by Technical Committee 225-SAP, V. Springer, (2012), 165 pp. 
Shu, X., Huang, B., Wu, H., Dong, Q. \& Burdette, E. G. (2011). Performance Comparison of Laboratory and Field Produced Pervious Concrete Mixtures. Construction and Building Materials, 25 (8), 3187-3192.

Zhong, R. \& Wille, K. (2015) Material Design and Characterization of High Performance Pervious Concrete. Construction and Building Materials, 98 (2015), 51-60. 